First publ. in: Proceedings of the International Symposium on Flavins and Flavoproteins,

Brighton, England, July 9 - 13, 1984, pp. 751-754

8-AZIDOFILAVINS: PHOTOAFFINITY LABELS FOR FLAVOPROTEINS

Sandro Ghisla

Faculty of Biology, University of Konstanz, D-7750 Konstanz, FRG

Paul F. Fitzpatrick, and Vincent Massey

Dep. of Biological Chemistry, Univ. of Michigan, Ann Arbor, Mi. 48109, USA

Introduction

The photoreactivity of flavins has, surprisingly, never been used as a tool for the specific labelling of active centers. In contrast, an FAD analog modified in the adenine moiety, 8-azido-adenosine-FAD has been used for labelling studies with D-amino acid oxidase and glucose oxidase (1). In the past decade arylazides have been studied intensively as photoactivity labels (2), they react covalently with protein residues upon photochemical generation of highly reactive nitrene intermediates. We have synthesized flavin coenzymes carrying the azido function at position 8 of the flavin since they were expected to be photolabelling agents. Here we describe some of their properties, and the labelling of three typical flavoproteins.

\title{
Bésults and Discussion
}

General Properties of 8-Azido-flavins

8-Azidoflavins can be synthesized conveniently by two routes: Diazotization of 8-aminoflavins and reaction of the (crystalline) diazonium perchlorate with $\mathrm{N}_{3}^{-}$lead to formation of (8) $\mathrm{N}_{3}$-flavins (Scheme 1 ). This method is convenient for the synthesis of $(8) \mathrm{N}_{3}$-flavin models and of larger amounts of derivatives. For the preparation of (8) $\mathrm{N}_{3}-f$ lavin coenzymes the method of choice is the direct conversion of 8-F-FMN or -FAD using $\mathrm{N}_{3}^{-}$as a nucleophile (Scheme 1). (8) $\mathrm{N}_{3}$-flavins are extremely photolabile; in the presence of various solvent molecules (8) N-R substituted flavins are formed probably 
by nitrene insertion. These products have been identified by comparison with derivatives obtained by direct substitution of the corresponding 8-F-flavin (Scheme 1). Thus $8\left(\mathrm{CH}_{3}-\mathrm{O}-\mathrm{NH}-\right.$ ) riboflavin, 8(HO-NH-)riboflavin, and $8\left(\mathrm{CH}_{3}-\mathrm{NH}-\mathrm{NH}-\right)$ riboflavin were obtained by reaction with (0)methylhydroxylamine, hydroxylamine, and monomethyl hydrazine respectively. These flavins are characterized by a strong absorption band in the 480-500 $\mathrm{nm}$ region $\left(\varepsilon \sim 20000\right.$ to $\left.35000 \mathrm{M}^{-1} \mathrm{~cm}^{-1}\right)$. $8(\mathrm{R}-0-\mathrm{NH}-)$ Riboflavins have an unusually low $\mathrm{pK}$ of $\sim 5.9$, which does not depend on the nature of the substituent $\mathrm{R}\left(\mathrm{R}=-\mathrm{H}\right.$ or $\left.\mathrm{CH}_{3}-\right)$, indicating that this $\mathrm{pK}$ reflects deprotonation at $\mathrm{N}(1)-\mathrm{H}$ of a p-quinoid flavin, as is observed in the case of the $8-0 \mathrm{H}-\mathrm{flavins}$. All of these $8(\mathrm{R}-\mathrm{N}-)$ flavins are easily and essentially quantitatively converted to $8-\mathrm{NH}_{2}$-flavins upon reduction with dithionite and subsequent reoxidation with oxygen. The reaction of (8) $\mathrm{N}_{3}-\mathrm{flavins}$ with sulfite leads to formation of 8-aminoflavins via a spectrally distinct intermediate. The latter probably results from addition of sulfite to the azido group. (8) $\mathrm{N}_{3}$-flavins also show a pronounced solvatochromy, suggesting their use as active site probes for lypophilic/lypophobic environments.

Scheme 1:

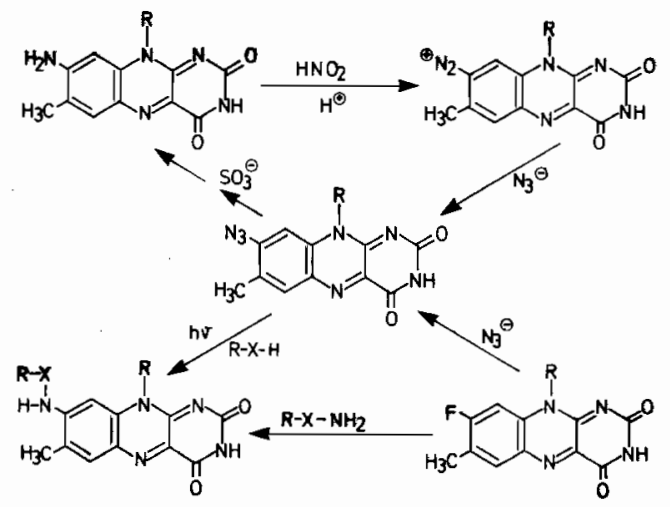

Interaction with Flavodoxins

(8) $\mathrm{N}_{3}-\mathrm{FMN}$ is bound tightly by M. elsdenii apoflavodoxin (3), with spectra1 shifts similar to those observed when other flavins are bound to the apoprotein, i.e. with a decrease in extinction at the wavelength maximum in the visible (from $\sim 22000$ to $\sim 17900 \mathrm{M}^{-1} \mathrm{~cm}^{-1}$ ) and the development of a pronounced shoulder at $470 \mathrm{~nm}$. The complex is very poorly photoreactive 
being orders of magnitude less sensitive than free $8-\mathrm{N}_{3}$-flavin, but with similar spectral changes. Precipitation of the irradiated protein with $5 \%$ trichloroacetic acid and dissolving in $8 \mathrm{M}$ guanidine.HCl revealed approximately $5 \%$ covalently labelled protein, consistent with the X-ray crystallographic studies, which show that the $8-\mathrm{CH}_{3}$ moiety of the flavin is exposed to solvent (4). It should be noted that photoreaction of the (8) $\mathrm{N}_{3}$-FAD-glutathione reductase complex, in which the flavin $8-\mathrm{CH}_{3}$ position a1so is in contact with solvent, does not lead to covalent modification of the protein (5).

Anteraction with Riboflavin Binding Protein

Riboflavin binding protein (6) forms a stoichiometric complex with (8) $\mathrm{N}_{3}$-riboflavin. The complex is much less photosensitive than free (8) $\mathrm{N}_{3}$-flavin, and irradiation must be carried out at $0-4^{\circ}$ in order to minimize dissociation, and subsequent photoreaction of free (8) $\mathrm{N}_{3}$-flavin. Approx. $30 \%$ of the flavin present after illumination is covalently bound to the protein.

Interaction with D-Amino Acid Oxidase

(8) $\mathrm{N}_{3}$-FAD is bound tightly by the apoenzyme (7) of this flavoprotein. In contrast to riboflavin binding protein, it is almost as light sensitive as free (8) $\mathrm{N}_{3}$-flavin (Fig. 1 ). The extent of covalent binding of the chromophore to the protein upon illumination was $\sim 17 \%$.

\section{Conclusions}

These studies demonstrate that the photoreactivity of $(8) \mathrm{N}_{3}$-flavocoenzymes turns the latter into potent affinity labels. In the three cases examined up to 50\% labelling was obtained per cycle of irradiation. The present studies cannot tell which amino acid residue might have reacted, however a correlation with the spectral properties of appropriately substituted 8-amino-flavins might provide such information. liapping studies with enzymes of known primary sequence should also provide direct information on which protein region is located near the flavin benzene moiety. 


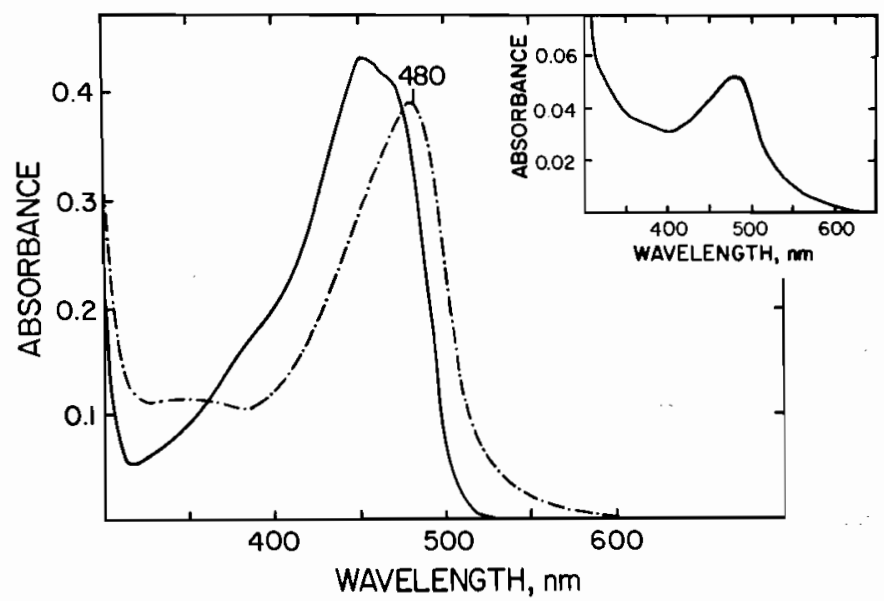

Fig. 1) Spectral changes occurring during the irradiation of (8)N 3 -FAD-D-amino acid oxidase

Spectrum (-) is that of apoenzyme $(50 \mu \mathrm{M})$ and $(8) \mathrm{N}_{3}-\mathrm{FAD}(30 \mu \mathrm{M})$ in $20 \mathrm{mM}$ pyrophosphate buffer, $\mathrm{pH} 8.5$ at $4^{\circ}$. Curve (-...) was obtained after $8 \mathrm{~s}$

- irradiation with white light $\left(\sim 8 \times 10^{6} \mathrm{erg} \mathrm{cm}^{-2} \mathrm{~s}^{-1}\right)$. The inset shows the spectrum of the chromophore covalently bound to the protein, obtained after exhaustive dialysis against $2 \mathrm{M} \mathrm{KBr}, 20 \mathrm{mM}$ pyrophosphate $\mathrm{pH} 8.5$ (which removes non-covalently bound flavin), and then against pyrophosphate minus $\mathrm{KBr}$.

\section{References}

1. Koberstein, R.: Eur. J. Biochem. 67, 223-229 (1976).

2. Bayley, H., and Knowles, J.R.: Methods in Enzymology 46, 69-114 (1977).

3. Mayhew, S.G.: Biochim. Biophys. Acta 235, 289-302 (1971).

4. Mayhew, S.G., and Ludwig, M.L.: The Enzymes, Vol. 12b, 57-109 (1975).

5. Krauth-Siegel, L., Ghisla, S., and Schirmer, H.: to be published.

6. Blankenhorn, G., Osuga, D.T., Lee, H.S., and Feeney, R.E.: Biochim. Biophys. Acta 386, 470-478 (1975).

- 7. Massey, V., and Curti, B.: J. Biol. Chem. 241, 3417-3423 (1966). 